\title{
Therapeutic Targets for the Treatment of Chronic Cough
}

\author{
N. A. Roe ${ }^{1}$ • F. T. Lundy ${ }^{1}$ - G. J. Litherland ${ }^{2}$ • L. P. A. McGarvey ${ }^{1}$
}

Published online: 2 May 2019

(C) The Author(s) 2019

\begin{abstract}
Purpose of Review Chronic cough, defined in adults as one lasting longer than 8 weeks, is among the commonest clinical problems encountered by doctors both in general practice and in hospital. It can exist as a distinct clinical problem or as a prominent and troublesome symptom for patients with common pulmonary conditions including asthma, chronic obstructive pulmonary disease and idiopathic pulmonary fibrosis.

Recent Findings Chronic cough impacts considerably on patients' daily-life activities and many patients are left frustrated by what they see as a complete lack of awareness among their doctors as how to treat their condition. Some of this arises from limited levels of physician knowledge about managing cough as a clinical problem but also because there are no very effective treatments that specifically target cough.

Summary In this article, we review the current clinical thinking regarding cough and the treatments that are currently used and those undergoing clinical development.
\end{abstract}

Keywords Cough $\cdot$ Cough receptor $\cdot$ Pharmacological targets $\cdot$ Novel $\cdot$ Ion channel

\section{Introduction}

Under normal physiological circumstances, coughing occurs with the primary purpose of protecting the lung from inhaled irritants and clearing unwanted airway secretions. Clinically, this defensive neural reflex can become dysregulated leading to episodes of cough evoked by relatively innocuous stimuli. This causes significant problems for those affected and is one of the most common reasons why people seek medical attention [1].

For clinical purposes, cough is defined as acute, sub-acute or chronic depending on its duration. An acute cough typically lasts no more than 3 weeks and is generally the result of a viral upper respiratory tract infection (URTI) associated with the common cold. Sub-acute cough lasts between 3 and 8 weeks

This article is part of the Topical Collection on Chronic Cough

L. P. A. McGarvey

1.mcgarvey@qub.ac.uk

1 Centre for Experimental Medicine, The Wellcome-Wolfson Building, School of Medicine, Dentistry and Biomedical Sciences, Queen's University Belfast, Belfast BT7 1NN, UK

2 Centre for Musculoskeletal Science, Institute of Biomedical and Environmental Health Research, University of the West of Scotland, Paisley, Scotland and is likely due to a slowly resolving post-viral cough. In adult patients, a cough persisting for more than 8 weeks is termed 'chronic' and can occur as an isolated clinical problem or associated with common respiratory and non-respiratory conditions such as chronic obstructive pulmonary disease (COPD), asthma, idiopathic pulmonary fibrosis (IPF), gastro-oesophageal reflux disease (GORD) and post-nasal drip or rhinosinusitis. Sometimes, despite extensive investigation and trials of empirical therapy, the cause for cough remains unexplained and in such instances is termed an idiopathic, or unexplained chronic cough [2, 3].

The prevalence of chronic cough may affect up to $13 \%$ of the general population and is associated with significant physical and psychological morbidity [4-8]. In a recent survey of almost 2000 people living with chronic cough, respondents reported their cough had impacted adversely on daily-life activities leading to many feeling fed-up and depressed [9]. Crucially, the majority reported undergoing numerous consultations with different physicians and receiving many unsuccessful therapeutic trials.

The increasing recognition of chronic cough as an important clinical problem has led to the development of guidelines to improve clinical care [10-12]. The underlying principle recommended in these guidelines is first to consider common respiratory diseases associated with obvious chest radiology and lung function abnormalities and then systematically 
evaluate the patient for other common causes such as asthma, reflux disease and upper airway disorders. While this approach is helpful and treatments such as inhaled steroids and anti-reflux therapy do help to control cough, a significant proportion of patients remain troubled [3]. In response to increasing numbers of patients referred for evaluation of cough, a number of specialist clinics have been set up within the UK, throughout Europe, the USA and Australasia. With a more detailed and expert assessment, there has been a fundamental change in understanding of the complex clinical aspects of cough. Central to this has been the notion that cough develops as a result of inflammation causing damage to the nerve cells (neuroinflammation) that conduct the cough signal from the lungs to the brain resulting in the clinical state now termed, cough hypersensitivity syndrome (CHS). Understanding the mechanisms responsible for this nerve damage (neuropathy) will be key to developing better treatments [13].

\section{Cough Hypersensitivity Syndrome}

The term 'Cough Hypersensitivity Syndrome' was first proposed by a European Respiratory Society Task Force and is defined as a 'clinical syndrome characterised by troublesome coughing triggered by low levels of thermal, mechanical or chemical exposure' [14]. The underlying concept is that the basal protective cough reflex transforms to a heightened state such that it is now triggered by low-level stimuli that would not usually cause cough. This state reflects precisely the clinical features reported by patients with CHS in so far as changes in ambient temperature, taking a deep breath, or talking, exposure to aerosol sprays or eating crumbly dry food are all sufficient to trigger bouts of coughing. The mechanisms responsible for this clinical state have yet to be determined but may parallel other disease concepts such as neuropathic pain. Following this line of thinking, cough triggered by innocuous stimuli might be similar to allodynia and excessive coughing in response to a noxious exposure (hypertussia) could be considered equivalent to hyperalgesia.

Although the causes of chronic cough vary, cough reflex hypersensitivity is likely to be a shared clinical and mechanistic characteristic. Therefore, while CHS may be present in a wide variety of conditions, common mechanisms likely underpin its development, offering great potential for the development of effective therapies.

\section{Treatment of Chronic Cough}

The recognition that chronic cough is characterised by hypersensitivity of the peripheral and central neural pathways involved in cough has expanded the range of potential therapeutic targets currently under evaluation. Here, we provide an update on these therapies with a focus on proposed site of action (peripheral or central) and preclinical and clinical findings to date. To do this, we undertook a detailed appraisal of published peer-reviewed research over the past 5 years (January 2013-December 2018) using PubMed for articles in English. The search terms included 'cough' plus 'receptor', 'pharmacological targets', 'novel', 'ion channel'. We also referred to publications accumulated because of our involvement in chronic cough research and treatment over the past 15 years. Articles resulting from these searches and relevant references cited in those articles were also reviewed. We also reviewed ClinicalTrials.gov over the last 5 years, and detail from this has been summarised in an accompanying table.

\section{Treatments with a Peripheral Site of Action}

Attenuating the heightened cough sensitivity while retaining the protective physiological capacity of the cough reflex is critical in the development of effective treatments. Sensory nerves of the airways express a variety of receptors and ion channels that when activated trigger cough. It seems logical that these channels/receptors may represent therapeutic targets for cough (Fig. 1). Here, we provide brief overview of experience with a number of these putative targets.

\section{TRP Channels}

Transient receptor potential (TRP) channels were first discovered and described in Drosophila in the 1960s but have since become important targets in chronic cough [15]. Manipulation of TRP channels on nociceptive neurons is proposed as an attractive strategy in the treatment of pain, and several drug developments targeting pain are focusing on these receptors. TRP channels are present in abundance in the airways and are expressed in many cell types of the airway including primary sensory afferent nerves, epithelial cells and smooth muscle cells [16].

TRP channels are cation channels comprising six transmembrane spanning domains with a pore between the fifth and sixth domains which allows the entry of calcium into a cell [17]. TRP channels are polymodal and directly activated by changes in temperature, chemicals, mechanical stimulation, $\mathrm{pH}$ and osmolality, which may evoke nociceptive responses including cough. The TRP channel superfamily encompasses 28 members that can be divided into 6 subfamilies based on sequence homology [17]. Of particular interest in relation to cough are members of the vanilloid (TRPV1, TRPV4), anykrin (TRPA1) and melastatin (TRPM8) families.

TRPV1 TRPV1 was the first channel to be considered as a key regulator of cough. TRPV1 is a polymodal channel activated by a variety of irritants including high temperature $\left(>43^{\circ} \mathrm{C}\right)$, 


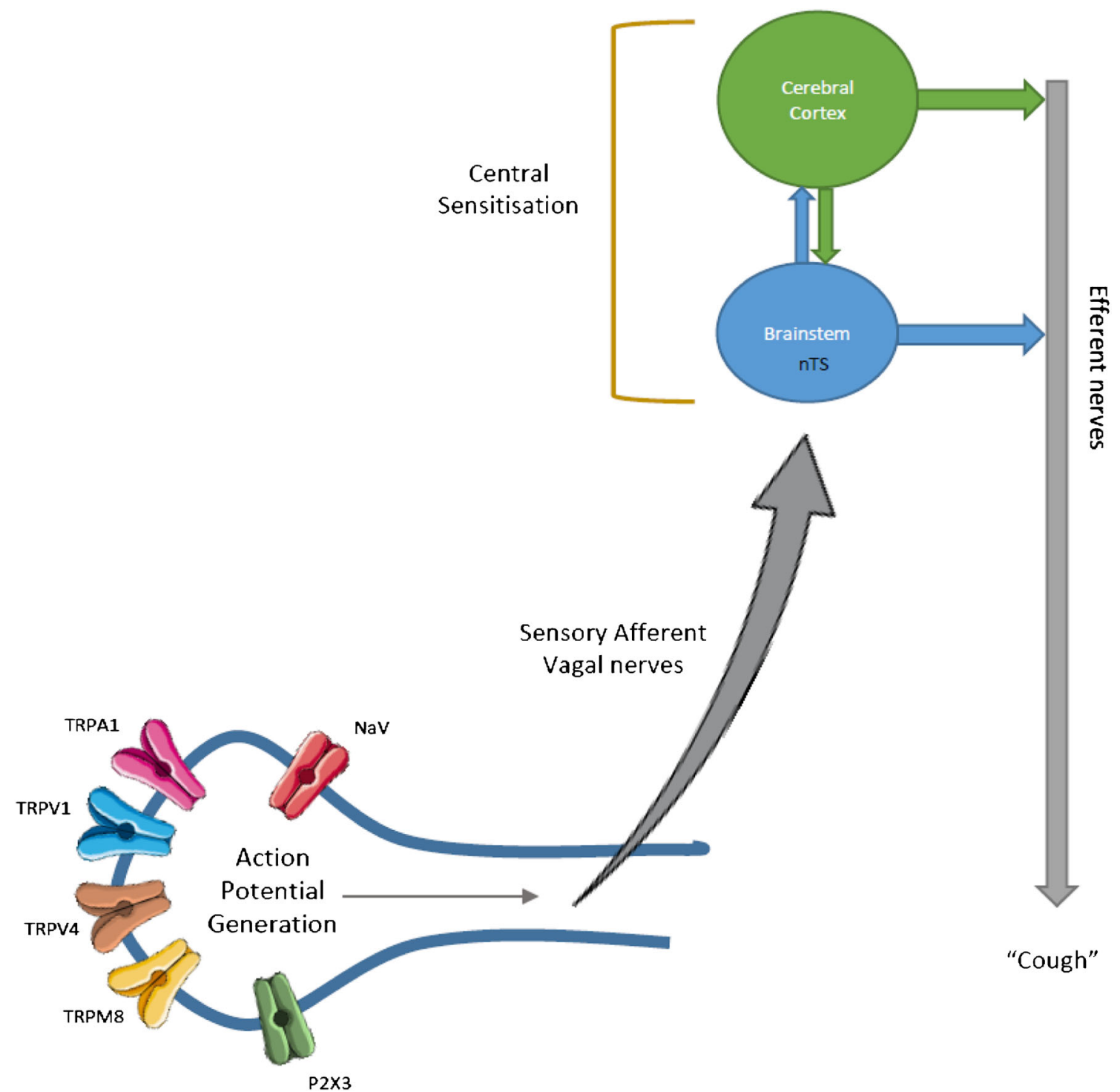

Fig. 1 Illustration of central and peripheral targets for antitussive agents. Current therapies in development that target the peripheral component of cough are transient receptor potential (TRP) channels (TRPV1, TRPV2, TRPV4 and TRPM8), purinergic receptors (P2X3) and voltage-gated sodium channels $(\mathrm{NaV})$. Peripheral sensory neurons project to regions of the brainstem including the nucleus tractus solitarius (nTS).

inflammatory mediators (e.g. prostaglandins, bradykinin), low $\mathrm{pH}(<5.9)$ and capsaicin $[17,18]$. Capsaicin, the pungent ingredient of hot chilli peppers, readily induces cough on inhalation. Recent randomised clinical trials of the TRPV1 antagonists, SB-705498 and XEN-D0501, have shown marked reduction in capsaicin-induced cough reflex sensitivity but failed to reduce cough frequency in chronic cough patients $[19,20]$. Based on evidence to date, it is unlikely that TRPV1 will be an effective therapeutic target for chronic cough.

TRPA1 The TRPA1 channel is activated by a range of physical and chemical factors including cold temperatures $(<$
Currently available centrally acting drugs target predominately $\mu$-opioid receptors and N-methyl-D-aspartate (NMDA) receptors. Neurokinin-1 receptor (NK-1R) antagonists and agonists of the alpha7 $(\alpha 7)$ subtype of nicotinic acetylcholine receptors (nAChRs) are in early stages of evaluation. Figure adapted from Smith JA et al. N Engl J Med 2016; 375: 1544-51

$17{ }^{\circ} \mathrm{C}$ ), mechanical stimulation, inflammatory mediators (e.g. prostaglandins, bradykinin) and acrolein (a component of cigarette smoke) [21, 22]. In both animal models and healthy humans, the TPRA1 agonist cinnamaldehyde induces a dose-dependent cough response [23]. Animal studies have shown effectiveness of TRPA1 antagonists in reducing cough in response to tussive challenges. The TRPA1 antagonist HC-030031 reduces cough responses to both exogenous and endogenous activators of TRPA1 in guinea pigs [24, 25]. Glenmark have developed a TRPA1 inhibitor, GRC 17536, which showed inhibition of citric acidinduced cough in guinea pigs [26]. However, in a doubleblinded placebo-controlled study, there was no reduction in 
cough frequency over $24 \mathrm{~h}$ or no reduction in citric acidinduced cough [16].

TRPV4 TRPV4 is recognised as an osmosensor and responds to diverse stimuli including non-noxious temperatures (27$35^{\circ} \mathrm{C}$ ), shear stress and mechanical stimulation. TRPV4 activation has been shown to be associated with the release of adenosine 5'-triphosphate (ATP). The TRPV4 agonist, GSK1016790a, induced depolarisation of vagus nerves in both animal and human tissue and induced cough in conscious guinea pigs which was blocked by the TRPV4 antagonist HC067047 [27, 28]. The mechanism underlying TRPV4induced ATP release has yet to be elucidated but a role for P2X3 receptors has been proposed [27]. However, a clinical trial with the TRPV4 antagonist, GSK2798745, was terminated early, presumably due to lack of efficacy.

\section{TRPM8}

TRPM8 is activated by cooling compounds such as menthol, icilin and eucalyptol. Although thought to play a role in cough induced by the inhalation of cold air, the TRPM8 agonist menthol also has protective and soothing effects and is a component of many over-the-counter cough remedies [29, 30]. The evidence for an antitussive role of TRPM8 is inconclusive and modulation of TRPM8 remains to be investigated as a potential target for chronic cough.

To date, pharmacological modulation of TRP channels for the treatment of cough has been disappointing. It remains to be seen if newer agents or strategies represent realistic options for the field of cough.

\section{Purinergic Receptors}

Purinergic receptors include subtypes of $\mathrm{P} 2 \mathrm{X}$ ion channel receptors which are activated by ATP and have received considerable attention recently as potential targets for the treatment of pain and cough. ATP is released as a result of cellular stress due to injury or infection and in lung conditions such as asthma or COPD, elevated airway levels have been reported [31, 32]. P2X3 receptors expressed on airway sensory afferent nerves are considered to have a role in development of mechanical allodynia and hyperalgesia in animal models of pain [33]. Gefapixant (MK-7264), previously known as AF-219, is a $\mathrm{P} 2 \mathrm{X} 3$ receptor antagonist recently shown to reduce cough frequency in a small placebo-controlled, crossover study of patients with unexplained chronic cough. High doses (600 $\mathrm{mg} \mathrm{bd}$ ) of the compound were used in this study, and all participants reported taste disturbances (hypogeusia or dysgeusia) [34]. A phase $2 b$ study of gefapixant at lower doses has reported efficacy with less taste disturbance [35]. Currently, this compound represents the most promising therapeutic target in development.

\section{Voltage-Gated Sodium Channels}

Voltage-gated sodium channels $(\mathrm{NaV})$ mediate the initiation and propagation of action potentials in afferent sensory nerves and represent a potential therapeutic target for cough. Lidocaine, a non-selective $\mathrm{NaV}$ channel blocker, attenuates the cough induced chemically by citric acid and capsaicin in awake guinea pigs [36, 37]. It has also been used clinically to alleviate cough and has been reported to be safe [38]. However, there are concerns regarding serious side effects of lidocaine including cardiac arrhythmias [39, 40]. A more targeted approach to $\mathrm{NaV}$ blockade seems sensible and of nine subtypes, NaV1.7, NaV1.8 and NaV1.9 are known to be expressed on vagal sensory neurons that innervate the lung and are likely to be involved in initiating cough [41, 42]. Selective inhibition of the NaV1.7 channel reduces excitability and sensory nerve activity and inhibits mechanically induced cough in guinea pigs [43, 44]. Recently, however, the results of a clinical trial of a novel blocker targeting NaV1.7 (GSK2339345) suggested no antitussive effect [45].

\section{Treatments with a Central Site of Action}

Sensory input from the upper and lower airways to the brainstem is relayed to higher brain regions where they modulate the varying sensory and motor responses that accompany coughing. The mechanisms underpinning the development of CHS may be akin to those described in pain where disordered peripheral and central neurophysiology are thought to be responsible for a variety of chronic pain syndromes. Chronic cough patients appear to have altered brain activity with evidence of both central sensitisation and dysfunctional inhibitory control [46]. A greater understanding of this disordered central processing is required and more selective targeting of pathways will be key to improved therapeutic control of troublesome coughing. Currently, the drugs used to treat or control cough that exert their therapeutic effect centrally do so at the expense of undesirable effects including sedation, respiratory depression and addiction. Here, we provide a brief overview of some of the common drugs with presumed central action used in treatment of chronic cough and highlight some more specific agents in early phase development.

\section{Opiates (Morphine Sulphate/Codeine/Tramadol)}

Opiates have been used to control cough for over 200 years. The notion that opiates are an effective cough suppressant has arisen from old studies in humans and animal studies [47, 48]. One commonly used drug is codeine, regarded as a weak opioid and found naturally in extracts of the poppy. The 
evidence for its efficacy is conflicting and given its unfavourable side effect profile, codeine is not an ideal antitussive [49-51].

The only randomised controlled study of opiates conducted in patients with chronic intractable cough was undertaken by Morice and colleagues which showed that $5 \mathrm{mg}$ of morphine sulphate twice daily for 2 months was an effective antitussive [52]. More recently, the antitussive properties of tramadol, an opioid medication with a similar structure to codeine and morphine, have been investigated in a pilot study and shown to be effective [53].

Dextomethorphan, which is an active ingredient of many popular brands of 'over-the-counter' cough preparations, is considered to have opiate properties. However, as its primary use is to control acute cough associated with the common cold, it is outside the scope of this review. However, a detailed review of this compound and other centrally acting drugs used for acute cough is available elsewhere [54].

\section{GABA-Related Compounds (Gabapentin, Pregabalin)}

Gabapentin and pregabalin are centrally acting neuromodulators primarily used for the treatment of neuropathic pain and epilepsy [55]. Both are structurally related to the inhibitory neurotransmitter, $\gamma$-aminobutyric acid (GABA), although their precise mode of action is unknown. They are known to modulate the release of neurotransmitters including substance $\mathrm{P}$ and may exert antitussive effects through attenuation of post-synaptic excitability [56]. One randomised placebocontrolled trial has shown that treatment of refractory chronic cough with gabapentin is both effective and well tolerated [57]. These efficacy claims have been supported in a recent systematic literature review [58].

Pregabalin has also been shown to improve cough in patients with what was termed sensory laryngeal neuropathy, and more recently, the combination of pregabalin and speech pathology treatment (SPT) was shown to be more effective in improving cough quality of life than SPT alone [59, 60]. Based on the existing evidence, gabapentin has recently received recommendation in the CHEST Guideline and Expert Panel Report as a treatment option for chronic cough [3].

\section{N-Methyl-D-Aspartate (NMDA) Receptors}

$\mathrm{N}$-methyl-D-aspartate (NMDA) receptors are expressed within the peripheral and central nervous system and are believed to play a role in the synaptic transmission of cough-associated vagal afferents which project from the lungs to the brainstem [61]. Dextromethorphan is thought to exert in effect at least in part through activation of NMDA receptors [62]. Preclinical studies have also suggested the antitussive effects of memantine, an NMDA receptor channel blocker used in the treatment of Alzheimer's disease [63, 64]. Despite this promising data, a recent small open-label pilot study of a novel NMDA receptor antagonist, V3381, showed only marginal efficacy and concerns regarding tolerability [65].

\section{Amitriptyline}

Amitriptyline is used for the treatment of depression and lower doses are also prescribed for the treatment of chronic neuropathic pain. This drug is an inhibitor of serotonin re-uptake but may also have effects on the muscarinic, adrenergic and histaminergic systems [66, 67]. Treatment of chronic cough with amitriptyline is reported to reduce cough, and in an open-label study of treatment for 10 days, improvements in cough frequency and severity when compared with codeine were reported [68]. However, in another study conducted over a longer duration (2 months), the efficacy of amitriptyline in patients with chronic cough was short-lived, and the majority of subjects discontinued treatment [69].

\section{Tachykinin Receptor Antagonists}

The tachykinins, substance P, neurokinin A and neurokinin B are released both from the peripheral endings of afferent nerves (predominately C-fibres) and from central neural structures. The tachykinin receptor, neurokinin 1 receptor has gained attention as a target for chronic cough treatment. The NK1R antagonist, aprepitant, has been shown to reduce cough in patients with lung cancer [70]. A pilot study of serlopitant, a centrally acting NK1R antagonist, resulted in significant improvements in objective cough frequency and sustained reductions in daytime cough frequency [71]. Currently, serlopitant is undergoing further clinical evaluation (Table 1). Orvepitant, another NK1 receptor antagonist, is also in phase 2 clinical trials (Table 1).

\section{Nicotinic Acetylcholine Receptors}

Nicotinic acetylcholine receptors, or nAChRs, respond to the neurotransmitter acetylcholine and to nicotine and are found in the central and peripheral nervous system. In a recent study of healthy non-smokers, marked antitussive effects of nicotine-containing vapours produced by e-cigarettes were reported [72]. It is now believed that the alpha7 ( $\alpha 7)$ subtype of the nAChRs, activating GABAergic interneurons in the brainstem, is responsible for the antitussive effect of nicotine [73]. Bradanicline, a selective agonist of the $\alpha 7$ subunit is currently being tested as a potential treatment for chronic cough in a phase 2 randomised, double-blind, doseescalation and crossover study. 


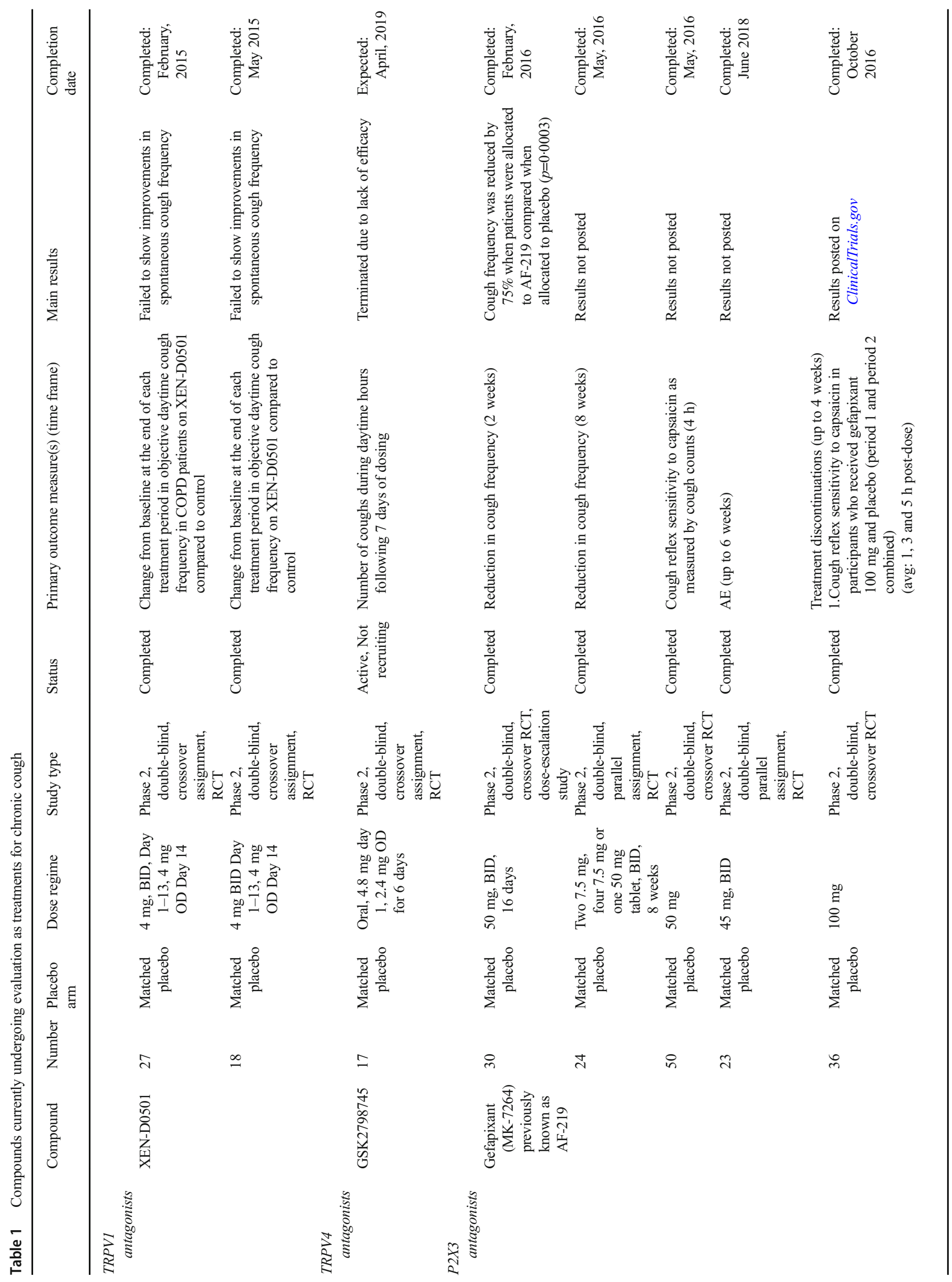




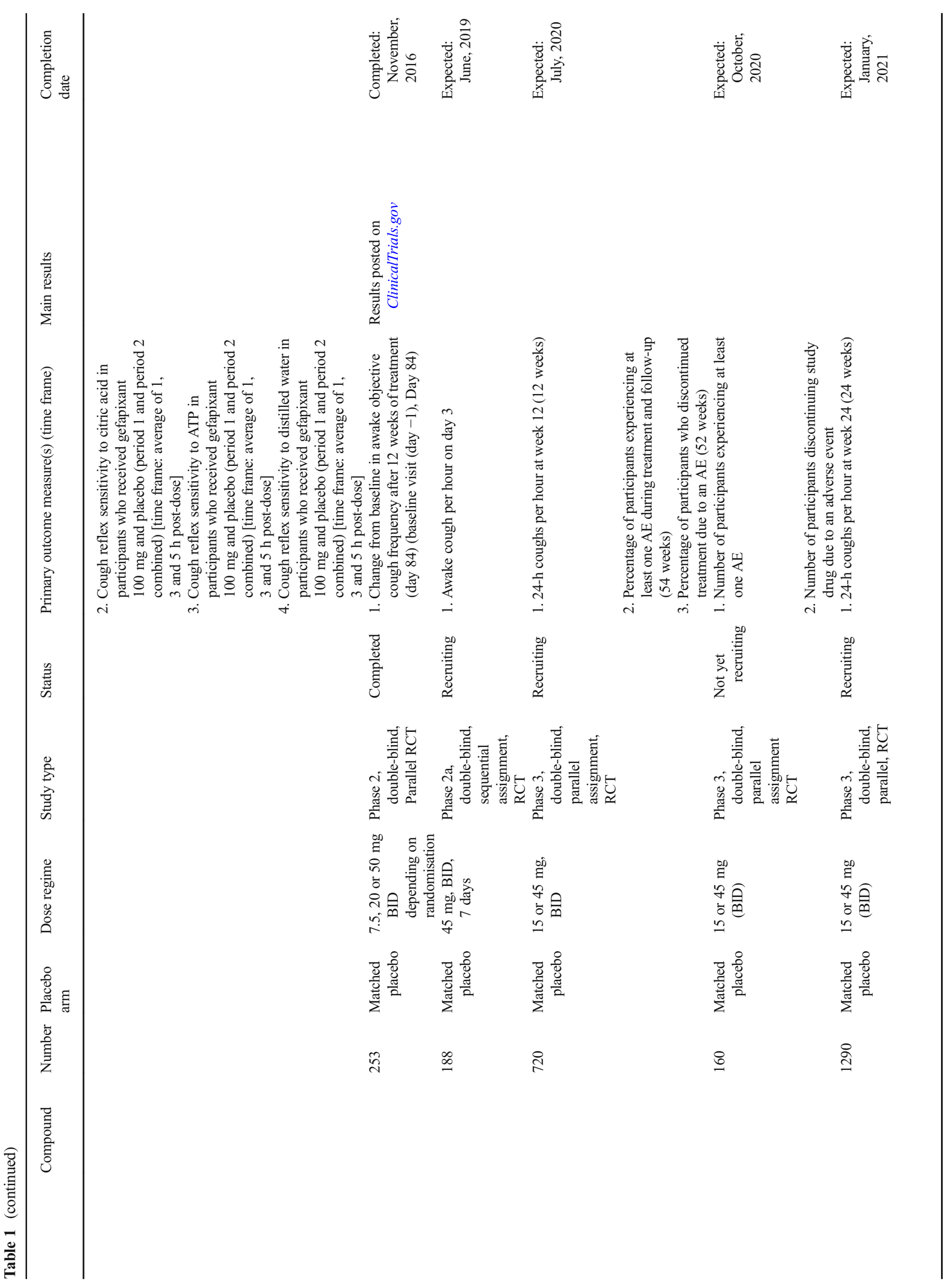




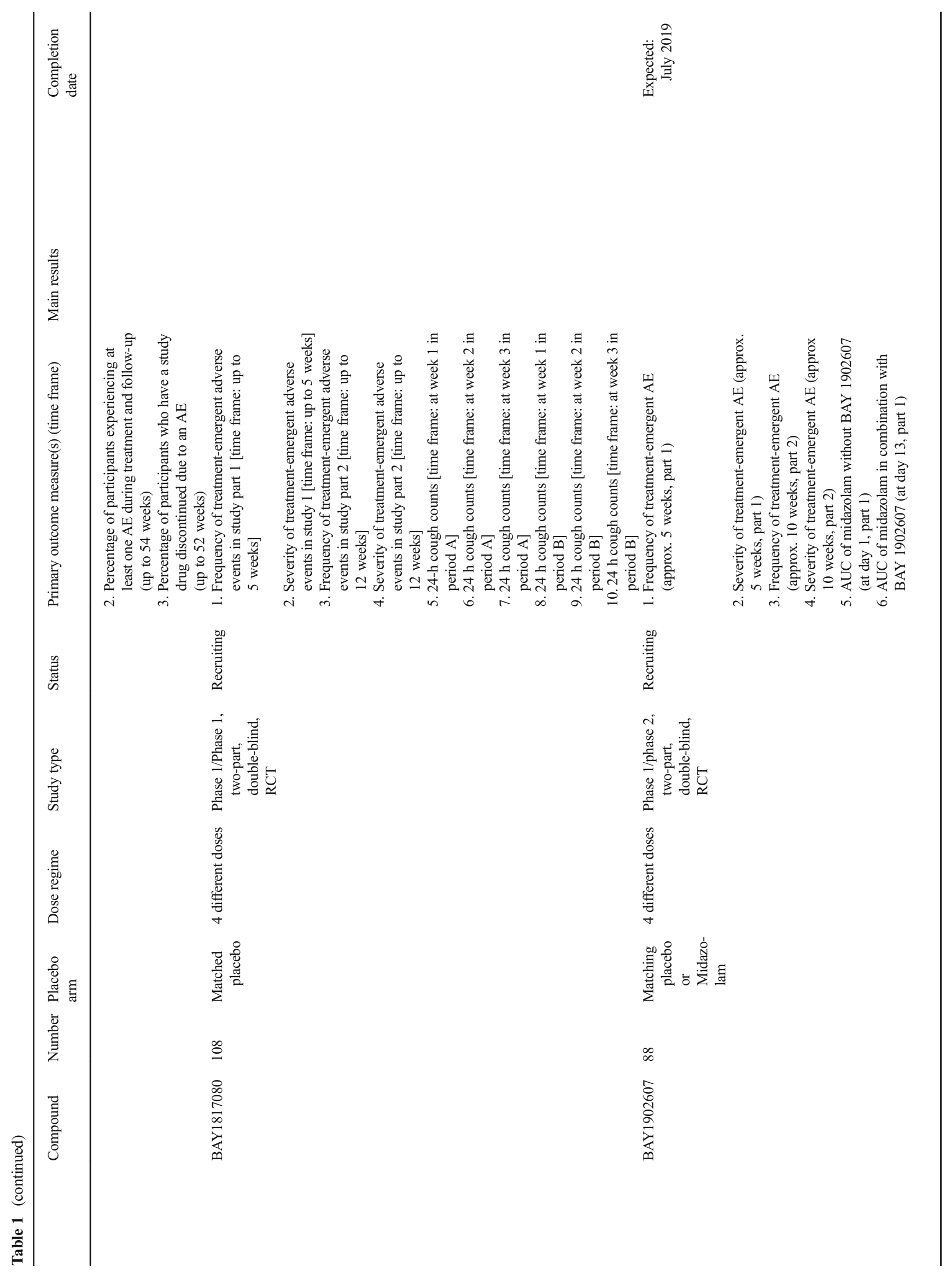




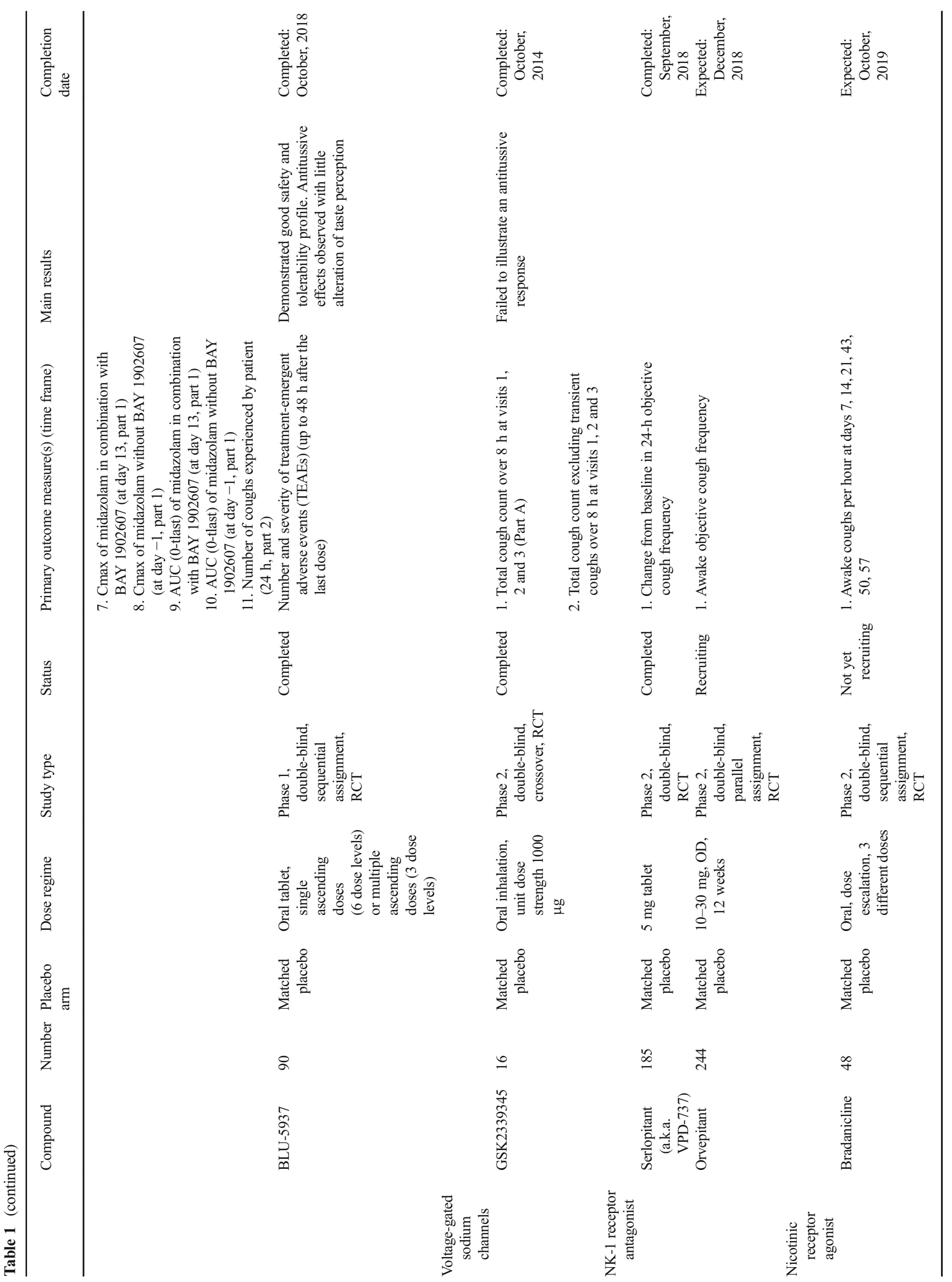


Other Medications for the Treatment of Chronic Cough

\section{Azithromycin}

A study by Hodgson et al. investigated the potential effects of azithromycin, a macrolide, on chronic cough [74]. Treatment with azithromycin for 8 weeks failed to improve health status of chronic cough patients when compared with placebo. This study however suggested there may be potential benefit of macrolide use in the treatment of cough associated with asthma.

\section{PA-101 Cromolyn Sodium Formulation}

PA-101 is a novel formulation of cromolyn sodium and thought to act as a mast cell stabiliser. It has undergone study in idiopathic chronic cough and in patients with pulmonary fibrosis, where cough is often a troublesome symptom. In a randomised placebo-controlled trial where PA-101 was delivered via a highefficiency eFlow nebuliser, no improvement in chronic idiopathic cough patients was observed [75]. However, the study did report reduction in cough in patients with idiopathic pulmonary fibrosis. These findings suggest some degree of heterogeneity in mechanisms responsible for CHS.

\section{Conclusion}

Chronic cough is an extremely common clinical problem that can exist in isolation or as the dominant symptom for patients across a wide range of common chronic respiratory conditions. Chronic cough is often difficult to control, largely because of the lack of effective medicines. Over the last two or three decades, there has been enormous progress in terms of optimising clinical evaluation, and gaining consensus on how to best manage patients with troublesome cough. There have also been important developments in the mechanistic understanding of cough and elucidating the associated neurobiology, and with this have come a number of promising therapeutic targets. Some of these are at advanced stages of clinical development with drugs targeting the $\mathrm{P} 2 \mathrm{X} 3$ receptor most promising. However, many challenges remain and partnerships are required, bringing clinicians and patients, scientists and industry together with government agencies to overcome these. This approach is likely to speed up drug discovery with the ultimate aim of providing better treatments for cough patients.

\section{Compliance with Ethical Standards}

Conflict of Interest This work was part of the BREATH project, by the EU under the Interreg VA Health and Life Science Programme. The views and opinions expressed in this paper do not necessarily reflect those of the European Commission or the SEUPB. 
Dr. Lundy reports grants from European Union Interreg VA Health \& Life Science Programme, grants from NC3Rs, personal fees from Grunenthal , during the conduct of the study.

N. Roe reports grants from European Union Interreg VA Health \& Life Science Programme, during the conduct of the study.

Dr. McGarvey reports grants from European Union Interreg VA Health \& Life Science Programme, grants from NC3R, personal fees from Afferent Pharmaceuticals, personal fees from Merck \& Co., Inc., grants and non-financial support from Chiesi, grants and non-financial support from Boehringer Ingelheim, grants and non-financial support from Glaxo Smith Kline, grants from Almirall, during the conduct of the study.

Human and Animal Rights and Informed Consent This article does not contain any studies with human or animal subjects performed by any of the authors.

Open Access This article is distributed under the terms of the Creative Commons Attribution 4.0 International License (http:// creativecommons.org/licenses/by/4.0/), which permits unrestricted use, distribution, and reproduction in any medium, provided you give appropriate credit to the original author(s) and the source, provide a link to the Creative Commons license, and indicate if changes were made.

\section{References}

Papers of particular interest, published recently, have been highlighted as:

•- Of major importance

1. Rui P, Kang K. National Hospital Ambulatory Medical Care Survey: 2015 Emergency Department Summary Tables. Available from: http://www.cdc.gov/nchs/data/ahcd/nhamcs_emergency/ 2015_ed_web_tables.pdf.

2. Chung KF, Pavord ID. Prevalence, pathogenesis, and causes of chronic cough. Lancet. 2008;371(9621):1364-74.

3. Gibson P, Wang G, McGarvey L, Vertigan AE, Altman KW, Birring SS. Treatment of unexplained chronic cough: CHEST guideline and expert panel report. Chest. 2016;149(1):27-44.

4. Ford AC, Forman D, Moayyedi P, Morice AH. Cough in the community: a cross sectional survey and the relationship to gastrointestinal symptoms. Thorax. 612006:975-9.

5. Cullinan P. Persistent cough and sputum: prevalence and clinical characteristics in south east England. Respir Med. 1992;86(2):143-9.

6. Birring SS, Prudon B, Carr AJ, Singh SJ, Morgan MD, Pavord ID. Development of a symptom specific health status measure for patients with chronic cough: Leicester Cough Questionnaire (LCQ). Thorax. 2003;58(4):339-43.

7. Adams RJ, Appleton SL, Wilson DH, Taylor AW, Ruffin RE. Associations of physical and mental health problems with chronic cough in a representative population cohort. Cough. 2009;5:10.

8. McGarvey LP, Carton C, Gamble LA, Heaney LG, Shepherd R, Ennis M, et al. Prevalence of psychomorbidity among patients with chronic cough. Cough. 2006;2:4.

9. Chamberlain SA, Garrod R, Douiri A, Masefield S, Powell P, Bucher C, et al. The impact of chronic cough: a cross-sectional European survey. Lung. 2015;193(3):401-8.

10. Morice AH, Fontana GA, Sovijarvi AR, Pistolesi M, Chung KF, Widdicombe $\mathrm{J}$, et al. The diagnosis and management of chronic cough. Eur Respir J. 2004;24(3):481-92.

11. Irwin RS, Baumann MH, Bolser DC, Boulet LP, Braman SS, Brightling CE, et al. Diagnosis and management of cough executive summary: ACCP evidence-based clinical practice guidelines. Chest. 2006;129(1 Suppl):1 s-23 s.

12. Irwin RS, French CT, Lewis SZ, Diekemper RL, Gold PM. Overview of the management of cough: CHEST Guideline and Expert Panel Report. Chest. 2014;146(4):885-9.

13.• Chung KF, McGarvey L, Mazzone S. Chronic cough and cough hypersensitivity syndrome. Lancet Respir Med. 2016;4(12):934-5. This state of the art paper provides the first detailed description of neuropathic cough as a clinical problem.

14.• Morice AH, Millqvist E, Belvisi MG, Bieksiene K, Birring SS, Chung $\mathrm{KF}$, et al. Expert opinion on the cough hypersensitivity syndrome in respiratory medicine. Eur Respir J. 2014;44(5):1132-48. This European Respiratory Society Task Force document advocates Cough Hypersensitivity Syndrome as a valid clinical concept.

15. Cosens DJ, Manning A. Abnormal electroretinogram from a Drosophila mutant. Nature. 1969;224(5216):285-7.

16. Fan Chung K. The Ninth 2016 International London Cough Symposium. Pulm Pharmacol Ther. 2017;47:1.

17. Clapham DE. TRP channels as cellular sensors. Nature. 2003;426(6966):517-24.

18. Tominaga M, Caterina MJ, Malmberg AB, Rosen TA, Gilbert H, Skinner K, et al. The cloned capsaicin receptor integrates multiple pain-producing stimuli. Neuron. 1998;21(3):531-43.

19. Belvisi MG, Birrell MA, Wortley MA, Maher SA, Satia I, Badri H, et al. XEN-D0501, a novel transient receptor potential vanilloid 1 antagonist, does not reduce cough in patients with refractory cough. Am J Respir Crit Care Med. 2017;196(10):1255-63.

20. Khalid S, Murdoch R, Newlands A, Smart K, Kelsall A, Holt K, et al. Transient receptor potential vanilloid 1 (TRPV1) antagonism in patients with refractory chronic cough: a double-blind randomised controlled trial. J Allergy Clin Immunol. 2014;134(1):56-62.

21. Bonvini SJ, Belvisi MG. Cough and airway disease: the role of ion channels. Pulm Pharmacol Ther. 2017;47:21-8.

22. Story GM, Peier AM, Reeve AJ, Eid SR, Mosbacher J, Hricik TR, et al. ANKTM1, a TRP-like channel expressed in nociceptive neurons, is activated by cold temperatures. Cell. 2003;112(6):819-29.

23. Birrell MA, Belvisi MG, Grace M, Sadofsky L, Faruqi S, Hele DJ, et al. TRPA1 agonists evoke coughing in guinea pig and human volunteers. Am J Respir Crit Care Med. 2009;180(11):1042-7.

24. Andre E, Gatti R, Trevisani M, Preti D, Baraldi PG, Patacchini R, et al. Transient receptor potential ankyrin receptor 1 is a novel target for pro-tussive agents. Br J Pharmacol. 2009;158(6):1621-8.

25. Grace M, Birrell MA, Dubuis E, Maher SA, Belvisi MG. Transient receptor potential channels mediate the tussive response to prostaglandin E2 and bradykinin. Thorax. 2012;67(10):891-900.

26. Mukhopadhyay I, Kulkarni A, Aranake S, Karnik P, Shetty M, Thorat S, et al. Transient receptor potential ankyrin 1 receptor activation in vitro and in vivo by pro-tussive agents: GRC 17536 as a promising anti-tussive therapeutic. PLoS One. 2014;9(5):e97005.

27. Bonvini SJ, Birrell MA, Grace MS, Maher SA, Adcock JJ, Wortley MA, et al. Transient receptor potential cation channel, subfamily V, member 4 and airway sensory afferent activation: role of adenosine triphosphate. J Allergy Clin Immunol. 2016;138(1):249-61 e12.

28. Belvisi M, Bonvini S, Grace M, Ching Y-M, Dubuis E, Adcock J, et al. Activation of airway sensory nerves: a key role for the TRPV4 channel. Am J Respir Crit Care Med. 2013;187:A5265.

29. Plevkova J, Biringerova Z, Gavliakova S. Thermo sensitive TRPM8 channel and its role in cold induced airway symptoms. Open Journal of Molecular and Integrative Physiology. 2012;2: 21-26. https://doi.org/10.4236/ojmip.2012.21004.

30. Xing H, Ling JX, Chen M, Johnson RD, Tominaga M, Wang CY, Gu J. TRPM8 mechanism of autonomic nerve response to cold in respiratory airway. Mol Pain. 2008 Jun 5;4:22. https://doi.org/10. 1186/1744-8069-4-22.

31. Idzko M, Hammad H, van Nimwegen M, Kool M, Willart MA, Muskens F, et al. Extracellular ATP triggers and maintains 
asthmatic airway inflammation by activating dendritic cells. Nat Med. 2007;13(8):913-9.

32. Lommatzsch M, Cicko S, Muller T, Lucattelli M, Bratke K, Stoll P, et al. Extracellular adenosine triphosphate and chronic obstructive pulmonary disease. Am J Respir Crit Care Med. 2010;181(9):928-34.

33. Prado FC, Araldi D, Vieira AS, Oliveira-Fusaro MC, Tambeli CH, Parada CA. Neuronal P2X3 receptor activation is essential to the hyperalgesia induced by prostaglandins and sympathomimetic amines released during inflammation. Neuropharmacology. 2013;67:252-8.

34. Abdulqawi R, Dockry R, Holt K, Layton G, McCarthy BG, Ford AP, Smith JA. P2X3 receptor antagonist (AF-219) in refractory chronic cough: a randomised, double-blind, placebo-controlled phase 2 study. Lancet.2015;385(9974):1198-20.

35. Smith J, Kitt M, Sher M, Butera P, Ford A. A phase 2 dose-escalation study with AF-219, a P2X3 antagonist for the treatment of chronic cough. Am J Respir Crit Care Med. 2016;193:A6524.

36. Svajdova S, Buday T, Brozmanova M. Lidocaine, a Non-selective Inhibitor of Voltage-Gated Sodium Channels, Blocks ChemicallyInduced Cough in Awake Naïve Guinea Pigs. Adv Exp Med Biol. 2019 Jan 13. https://doi.org/10.1007/5584_2018_326.

37. Venkatasamy R, McKenzie A, Page CP, Walker MJ, Spina D. Use of within-group designs to test anti-tussive drugs in conscious guinea-pigs. J Pharmacol Toxicol Methods. 2010;61(2):157-62.

38. Lim KG, Rank MA, Hahn PY, Keogh KA, Morgenthaler TI, Olson EJ. Long-term safety of nebulized lidocaine for adults with difficultto-control chronic cough: a case series. Chest. 2013;143(4):1060-5.

39. Chong CF, Chen CC, Ma HP, Wu YC, Chen YC, Wang TL. Comparison of lidocaine and bronchodilator inhalation treatments for cough suppression in patients with chronic obstructive pulmonary disease. Emerg Med J. 2005;22(6):429-32.

40. Udezue E. Lidocaine inhalation for cough suppression. Am J Emerg Med. 2001;19(3):206-7.

41. Kwong K, Carr MJ, Gibbard A, Savage TJ, Singh K, Jing J, et al. Voltage-gated sodium channels in nociceptive versus nonnociceptive nodose vagal sensory neurons innervating guinea pig lungs. J Physiol. 2008;586(5):1321-36.

42. Sun H, Kollarik M, Undem BJ. Blocking voltage-gated sodium channels as a strategy to suppress pathological cough. Pulm Pharmacol Ther. 2017;47:38-41.

43. Muroi Y, Ru F, Kollarik M, Canning BJ, Hughes SA, Walsh S, et al. Selective silencing of $\mathrm{Na}(\mathrm{V}) 1.7$ decreases excitability and conduction in vagal sensory neurons. J Physiol. 2011;589(Pt 23:5663-76.

44. Muroi Y, Ru F, Chou YL, Carr MJ, Undem BJ, Canning BJ. Selective inhibition of vagal afferent nerve pathways regulating cough using Nav 1.7 shRNA silencing in guinea pig nodose ganglia. Am J Phys Regul Integr Comp Phys. 2013;304(11):R1017-23.

45. Smith JA, McGarvey LPA, Badri H, Satia I, Warren F, Siederer S, et al. Effects of a novel sodium channel blocker, GSK2339345, in patients with refractory chronic cough. Int J Clin Pharmacol Ther. 2017;55(9):712-9.

46. Ando A, Smallwood D, McMahon M, Irving L, Mazzone SB, Farrell MJ. Neural correlates of cough hypersensitivity in humans: evidence for central sensitisation and dysfunctional inhibitory control. Thorax. 2016;71(4):323-9.

47. Sevelius H, McCoy JF, Colmore JP. Dose response to codeine in patients with chronic cough. Clin Pharmacol Ther. 1971;12(3):449-55.

48. May AJ, Widdicombe JG. Depression of the cough reflex by pentobarbitone and some opium derivatives. Br J Pharmacol Chemother. 1954;9(3):335-40.

49. Smith J, Owen E, Earis J, Woodcock A. Effect of codeine on objective measurement of cough in chronic obstructive pulmonary disease. J Allergy Clin Immunol. 2006;117(4):831-5.

50. Bolser DC, Davenport PW. Codeine and cough: an ineffective gold standard. Curr Opin Allergy Clin Immunol. 2007;7(1):32-6.

51. Hua K, Wang T, Li C, Li S, Ma X, Li M, et al. Abnormal degree centrality in chronic users of codeine-containing cough syrups: a resting-state functional magnetic resonance imaging study. Neuroimage Clin. 2018;19:775-81.

52. Morice AH, Menon MS, Mulrennan SA, Everett CF, Wright C, Jackson J, et al. Opiate therapy in chronic cough. Am J Respir Crit Care Med. 2007;175(4):312-5.

53. Dion GR, Teng SE, Achlatis E, Fang Y, Amin MR. Treatment of neurogenic cough with tramadol: a pilot study. Otolaryngol Head Neck Surg. 2017;157(1):77-9.

54. Dicpinigaitis PV, Morice AH, Birring SS, McGarvey L, Smith JA, Canning BJ, et al. Antitussive drugs-past, present, and future. Pharmacol Rev. 2014;66(2):468-512.

55. Fan H, Yu W, Zhang Q, Cao H, Li J, Wang J, et al. Efficacy and safety of gabapentin $1800 \mathrm{mg}$ treatment for post-herpetic neuralgia: a meta-analysis of randomized controlled trials. J Clin Pharm Ther. 2014;39(4):334-42.

56. Fink K, Dooley DJ, Meder WP, Suman-Chauhan N, Duffy S, Clusmann $\mathrm{H}$, et al. Inhibition of neuronal $\mathrm{Ca}(2+)$ influx by gabapentin and pregabalin in the human neocortex. Neuropharmacology. 2002;42(2):229-36.

57. Ryan NM, Birring SS, Gibson PG. Gabapentin for refractory chronic cough: a randomised, double-blind, placebo-controlled trial. Lancet. 2012;380(9853):1583-9.

58. Shi G, Shen Q, Zhang C, Ma J, Mohammed A, Zhao H. Efficacy and safety of gabapentin in the treatment of chronic cough: a systematic review. Tuberc Respir Dis (Seoul). 2018;81(3):167-74.

59. Vertigan AE, Kapela SL, Ryan NM, Birring SS, McElduff P, Gibson PG. Pregabalin and speech pathology combination therapy for refractory chronic cough: a randomized controlled trial. Chest. 2016;149(3):639-48.

60. Halum SL, Sycamore DL, McRae BR. A new treatment option for laryngeal sensory neuropathy. Laryngoscope. 2009;119(9):1844-7.

61. Canning BJ. Central regulation of the cough reflex: therapeutic implications. Pulm Pharmacol Ther. 2009;22(2):75-81.

62. Franklin $\mathrm{PH}$, Murray TF. High affinity $[3 \mathrm{H}]$ dextrorphan binding in rat brain is localised to a noncompetitive antagonist site of the activated N-methyl-D-aspartate receptor-cation channel. Mol Pharmacol. 1992;41(1):134 46.

63. Kamei J, Tanihara H, Kasuya Y. Antitussive effects of two specific kappa-opioid agonists, U-50,488H and U-62,066E, in rats. Eur J Pharmacol. 1990;187(2):281-6.

64. Smith JA, Hilton ECY, Saulsberry L, Canning BJ. Antitussive effects of memantine in guinea pigs. Chest. 2012;141(4):996-1002.

65. Young E, Pawsey S, Woodcock A, Smith J. An open label study of V3381, a novel N-methyl-D-aspartate receptor (NMDA-R) antagonist in chronic cough (abstract). Lung. 2012;19:63.

66. Gillman PK. Tricyclic antidepressant pharmacology and therapeutic drug interactions updated. Br J Pharmacol. 2007;151(6):737-48.

67. Lawson K. A brief review of the pharmacology of amitriptyline and clinical outcomes in treating fibromyalgia. Biomedicines. 2017;5(2).

68. Jeyakumar A, Brickman TM, Haben M. Effectiveness of amitriptyline versus cough suppressants in the treatment of chronic cough resulting from postviral vagal neuropathy. Laryngoscope. 2006;116(12):2108-12.

69. Bowen AJ, Nowacki AS, Contrera K, Trask D, Kaltenbach J, Milstein CF, et al. Short- and long-term effects of neuromodulators for unexplained chronic cough. Otolaryngol Head Neck Surg. 2018;159(3):508-15.

70. Harle A, Smith J, Molassiotis A, Lofthouse K, Dockry R, Russell P, et al. A placebo-controlled trial of aprepitant for cough in lung cancer. J Clin Oncol. 2015;33(29_suppl):2-2.

71. Smith J, Allman D, Badri H, Miller R, Morris J, Satia I, et al. The neurokinin-1 receptor antagonist orvepitant is a novel anti-tussive therapy for chronic refractory cough: results from a phase 2 study (VOLCANO-1). Am J Respir Crit Care Med. 2017;195:A2672. 
72. Dicpinigaitis PV, Lee Chang A, Dicpinigaitis AJ, Negassa A. Effect of e-cigarette use on cough reflex sensitivity. Chest. 2016;149(1): $161-5$.

73. Dicpinigaitis P, Canning B, DeVita R, Perelman M, Liu Q, Hay D, et al. The antitussive effects of alpha7 $(\alpha 7)$ nicotinic receptor agonists. Eur Respir J. 2017;50:OA4409.

74. Hodgson D, Anderson J, Reynolds C, Oborne J, Meakin G, Bailey $\mathrm{H}$, et al. The effects of azithromycin in treatment-resistant cough: a randomized, double-blind, placebo-controlled trial. Chest. 2016;149(4):1052-60.
75. Birring SS, Wijsenbeek MS, Agrawal S, van den Berg JWK, Stone $\mathrm{H}$, Maher TM, et al. A novel formulation of inhaled sodium cromoglicate (PA101) in idiopathic pulmonary fibrosis and chronic cough: a randomised, double-blind, proof-of-concept, phase 2 trial. Lancet Respir Med. 2017;5(10):806-15.

Publisher's Note Springer Nature remains neutral with regard to jurisdictional claims in published maps and institutional affiliations. 